\title{
Práticas-políticas curriculares cotidianas como possibilidades de resistência aos clichês e à Base Nacional Comum Curricular (BNCC)
}

Carlos Eduardo Ferraço

Universidade Federal do Espírito Santo

\section{Resumo}

O texto problematiza as relações entre currículo e cotidiano escolar assumindo como pressuposto básico a dimensão política das práticas a partir de resultados de pesquisas realizadas em escolas públicas do Espírito Santo. Utiliza como principais intercessores teóricos Certeau, Alves, Deleuze e Guattari, buscando estabelecer enredamentos entre as pesquisas com os cotidianos. Defende a potência das práticas-políticas curriculares tecidas em redes nos cotidianos das escolas como possibilidades de resistência frente aos clichês e aos mecanismos de controle, de apagamento das diferenças e de diminuição da vida produzidos pela atual proposta de uma base nacional comum curricular.

Palavras-chave: Currículo. Cotidiano. Clichê. Práticas-políticas. Resistência. 


\section{Everyday curricular politica-practice as possibilities of resitance to cliches and Common National Curriculum Base (BNCC)}

\section{Abstract}

This paper problematizes the relationship between curriculum and school everyday life, considering as basic assumption the political dimension of the practices, based on results of studies carried out in public schools in the State of Espirito Santo, Brazil. It uses as main theoretical intercessors Certeau, Alves, Deleuze and Guattari, seeking to establish networks with the studies on school everyday life. It defends the power of the curricular political practices woven in networks in school everyday life as possibilities of resistance against the cliches and the mechanisms of control; of difference extinction; and of diminution of life produced by the current proposal of a common national curricular base.

Keywords: Curriculum. Everyday life. Cliche. Political Practice. Resistance. 


\section{Prácticas-políticas curriculares cotidianas como posibilidad de resistencia a los clichés y a la Base Nacional Común Curricular (BNCC)}

\section{Resumen}

El texto problematiza las relaciones entre currículo y cotidiano escolar, asumiendo como supuesto básico la dimensión política de las prácticas, a partir de resultados de pesquisas realizadas en escuelas públicas de Espírito Santo. Utiliza como principales intercesores teóricos Certeau, Alves, Deleuze y Guattari, buscando establecer enredos entre las pesquisas con los cotidianos. Defiende la potencia de las prácticas-políticas curriculares tejidas en redes en los cotidianos de las escuelas como posibilidades de resistencia a los clichés e los mecanismos de control, de eliminación de las diferencias y de disminución de la vida producidos por la actual propuesta de una base nacional común curricular.

Palabras-Ilave: Currículo. Cotidiano. Cliché. Prácticas-políticas. Resistencia.

\section{Pratiques-politiques curriculaires quotidiennes comme possibilités de résistance aux clichés et à la base nationale commune curriculaire (BNCC)}

\section{Résumé}

Le text problématise la relation entre le curriculum scolaire et le quotidien de l'école, en prenant comme présuposé basique la dimension politique des pratiques, a partir de résultats de recherches prises dans des écoles publiques de l'Espírito Santo. On utilise comme les principaux intercesseurs théoriques Certeau, Alves, Deleuze et Guattari, en cherchant établir des enchêvetrements des recherches avec les quotidiens. On défend la puissance des pratiques politiques des matières scolaires tissées en réseaux dans les quotidiens des écoles comme des possibilités de résistance face aux clichés et aux mécanisme de contrôle, de suppression des différences et de la réduction de la vie produits par la courrante proposition d'une base nationale commune du curriculum scolaire.

Mots-clés: Curriculum. Quotidien. Clichés. Pratiques politiques. Résistance. 


\section{Considerações iniciais}

Como já afirmado em outros artigos, em nossas pesquisas temo-nos empenhado em produzir dados em meio às narrativas-imagens (Alves, 2008) de educadores e de estudantes com o intuito de afirmar a potência das dimensões ético-estético-políticas de suas ações-teorias como possibilidade de problematização e de resistência (Revel, 2011) tanto aos clichês (Deleuze \& Guattari, 2001) que instauram-se nas verdades prontas e nas explicações simplificadoras para os acontecimentos dos cotidianos das escolas, quanto aos mecanismos de assujeitamento e de desvalorização das práticas que acontecem nesses cotidianos.

Para tanto, assumimos como nossos intercessores teóricos principais os conceitos de resistência (Revel, 2011), currículos em redes (Alves 2010, Ferraço, 2016), rizoma, caos, diferença, multiplicidade, acaso e devir (Deleuze \& Guattari, 1996, 2001, 2004), pensados como totalidades fragmentárias, intensidades e agenciamentos que tecem os currículos nos cotidianos escolares envolvidos com as pesquisas.

Ao discutirem sobre a relação entre produção de conceitos e plano de imanência, Deleuze e Guattari (2001) asseveram que não há conceitos que possam ser considerados como simples e que todo conceito possui componentes e define-se por eles. Assim, podemos pensar que os conceitos são, de modo geral, multiplicidades ao mesmo tempo em que constituem-se como um todo. Ao possuir contornos irregulares e definidos pelos seus componentes, o conceito se institui como um todo fragmentário ao mesmo tempo em que remete a um problema sem o qual não teria sentido.

Ainda a partir das questões acenadas por Deleuze e Guattari (2001) podemos inferir que, em sua composição, todo conceito é transversalizado por elementos vindos de outros conceitos que, obviamente, respondiam a outros problemas. Assim, em sua composição cada conceito se evidencia, se institui e se constitui como fragmentação, não se encaixando como peça de um quebra-cabeça, já que suas bordas irregulares não coincidem com as de outros conceitos. A esse respeito, Deleuze e Guattari (2001, p. 46) se manifestam:

Em toda parte reencontramos o mesmo estatuto pedagógico do conceito: uma 'multiplicidade', uma superfície ou volume absolutos, auto-referentes, compostos de um certo número de variações intensivas inseparáveis segundo uma ordem de vizinhança, e percorridos por um ponto em estado de sobrevoo. O conceito é o contorno, a configuração, a constelação de um acontecimento por vir.

As provocações dos autores (2001) em relação ao que entendem por um conceito nos ajudam a sustentar a ideia que o conceito de clichê traz necessariamente em sua composição franjas de outros conceitos, o que nos permite pensar no clichê 
como algo que não pode ser representado por uma totalidade-coerência. Ou seja, para efeito de nossas pesquisas, como já afirmamos antes, todo clichê produzido nos cotidianos das escolas traz, em tese, possibilidades de sua desconstrução. Como defendem Deleuze \& Guattari (2001, p. 51):

Os conceitos filosóficos são totalidades fragmentárias que não se ajustam umas às outras, já que suas bordas não coincidem. Eles nascem de lances de dados, não compõem um quebra-cabeças. E, todavia, eles ressoam [...]. Os conceitos são agenciamentos.

Na pesquisa encerrada em 2017, problematizamos as imagens-narrativas cotidianas que produziam clichês e que eram, ao mesmo tempo, subvertidas pelos próprios praticantes à medida que, ao acaso e em meio ao caos (Deleuze \& Guattari, 2001), viviam-praticavam encontros (Bhabha, 1998), conversas (Certeau, 1994; Deleuze \& Guattari, 2001), experiências (Foucault, 2015), acontecimentos (Deleuze, 2007c), entre outros fluxos-forças que insurgiam nos planos de imanência (Deleuze \& Guattari, 2001) com os quais, na condição de pesquisador-praticante (Ferraço, 2003, 2016), desenvolvíamos nossas investigações.

Ou seja, ao mesmo tempo em que nossas problematizações foram acontecendo, fomos nos dando conta de que cada discurso-ação de produção de clichês trazia consigo, de modo sutil e como um fenômeno fronteiriço (Deleuze \& Guattari, 2007), a possibilidade de sua desconstrução, de sua dissolução e isso estava relacionado com o tipo de experiência, conversa, encontro, acontecimento ou qualquer movimentointensidade que insurgia nos cotidianos, impossíveis de serem previstos na ordem do acaso.

Concordando com Deleuze (2007a) quando afirma que os clichês se multiplicam a todo instante, pensamos então sobre como podemos problematizar essa questão sem cair em novos clichês ou, pelos menos, sem reificar os clichês já existentes. Com isso, considerando que "O que nos precipita num devir pode ser qualquer coisa, a mais inesperada, a mais insignificante. Você não se desvia da maioria sem um pequeno detalhe que vai se pôr a estufar, e que lhe arrasta" (Deleuze \& Guattari, 2008b, p. 89), vamos nos dar conta do fato de que não temos controle sobre o que nos acontece. Ou seja, a força que nos arrasta em devir é da ordem do inesperado, do insignificante, do detalhe, dos pequenos fatos que nos tomam de súbito e nos arrancam de nossos lugares de acomodação, das nossas verdades, evidenciando, assim, a dimensão do acaso na luta contra essas verdades-clichês. Para Deleuze (2000, p. 218)

Acreditar no mundo é o que mais nos falta; nós perdemos completamente o mundo, nos desapossaram dele. Acreditar no mundo significa principalmente suscitar acontecimentos, mesmo pequenos, que escapem ao controle, ou engendrar novos espaços-tempos, mesmo de superfície ou volume reduzidos. É o que você chama de pietàs. É ao nível de cada tentativa que se avaliam a capacidade de resistência ou, ao contrário, a submissão a um controle. Necessita-se ao mesmo tempo de criação e povo. 


\title{
Acaso, clichê e fenômenos fronteiriços
}

Mas como Deleuze (2007a) entende a força do acaso na superação dos clichês? Ao pensar sobre o trabalho do pintor Cezànne, Deleuze (2007a) infere que uma primeira pista estaria no furor do artista contra o clichê, levando-o às vezes a transformá-lo em paródia. Como pondera o autor (2007a, p. 92), "Ele queria exprimir algo, mas, antes de fazê-lo, tinha que lutar contra o clichê de cabeça de hidra do qual jamais conseguia cortar a última".

Assim, a partir da luta de Cézanne contra a produção de clichês, Deleuze (2007a) sugere a possibilidade de chegar-se a um conhecimento intuitivo, à medida que conseguimos nos livrar da obsessão do conceito e das soluções universais. Na situação vivida por Cézanne, citada por Deleuze (2007a), no lugar da abstração e do intelecto, a paródia e a intuição!

De acordo com Deleuze (2007a), uma das formas de lutar-se contra o clichê estaria, então, na astúcia, obstinação e prudência empreendidas por Cézanne na feitura de cada quadro, uma vez que, "Tudo está na tela, mesmo o próprio pintor, antes que a pintura comece. Assim, o trabalho do pintor é repetidamente deslocado, só podendo vir depois, posteriormente: trabalho manual do qual surgirá a Figura" (p. 101).

Se para Deleuze (2007a) a astúcia, a obstinação e a prudência aliadas à intuição e à paródia são alternativas buscadas por Cézanne para não sucumbir ao clichê, no caso do pintor Bacon, o autor (2007a) destaca a força do acaso, ou das marcas livres como um movimento importante da relação que o artista estabeleceu com sua pintura. $A$ esse respeito, Deleuze (2007a, p. 97) infere que:

\begin{abstract}
Se considerarmos, com efeito, uma tela antes do trabalho do pintor, parece que todos os lugares se equivalem, são todos igualmente 'prováveis'. E se eles não se equivalem, é porque a tela é uma superfície determinada, com bordas e um centro; mas sobretudo em função daquilo que o pintor quer fazer e do que ele tem na cabeça: tal lugar tem privilégio com relação a esse ou àquele projeto [...]. Mas, nesse exato momento, quando já comecei, como fazer com que aquilo que pinto não seja um clichê? Será preciso fazer rapidamente 'marcas livres' no interior da imagem pintada para destruir a figuração nascente e dar uma chance à Figura, que é o próprio improvável.
\end{abstract}

Ao comentar então o modo como Bacon luta contra o clichê, Deleuze (2007a) pensa que as marcas livres feitas pelo pintor na imagem são, antes de tudo, acidentais, isto é, produzidas ao acaso, de modo fortuito. Um tipo de acaso que não designaria uma possibilidade, mas uma dada escolha, uma ação sem nenhuma probabilidade. Como entende o autor (2007a, p. 97-98) "Essas marcas são não-representativas, justamente porque dependem do ato ao acaso e nada exprimem que se refira à imagem visual: 
elas só dizem respeito à mão do pintor". Ainda para Deleuze (2007a, p. 98):

Do princípio ao fim, o acidente, o acaso nesse segundo sentido, terá sido ato, escolha, um determinado tipo de ato e de escolha. O acaso, segundo Bacon, não é separável de uma possibilidade de utilização. É o acaso manipulado, diferente das probabilidades concebidas ou vistas.

Na condição de pesquisador-praticante (Ferraço, 2003, 2016) e, ainda, (co)movido pela força do acaso na produção do que escapa à representação, à rostidade, ao que ameaça o conformismo, à padronização e à mesmidade emergiu, a partir da pesquisa encerrada em 2017, a possibilidade de nos forçar a pensar com Deleuze \& Guattari (2007) o que eles chamam de fenômenos fronteiriços, isto é, aqueles acontecimentos involuntários que se dão na indefinição, nos interstícios, nos entrelugares, nas fronteiras, no vácuo das velocidades, entre as linhas de força que tensionam as produções dos clichês e que são tecidos em redes com as práticaspolíticas curriculares cotidianas.

Desse modo, temos assumido como hipótese de nossa atual pesquisa que também é neste instante do que não está totalmente previsto, do que não pode ser determinado por completo, daquilo que nunca se esgota e não se deixa controlar por inteiro porque não se restringe à tentativa de previsibilidade dos planejamentos curriculares, porque evidencia-se nas falas, nos gestos e nas marcas que insurgem ao acaso das conversas, dos encontros e dos acontecimentos cotidianos, tais como as pinceladas aleatórias de Bacon que teremos alguma chance de rasurar as representações-clichê do currículo.

No texto "1227 - Tratado de nomadologia: a máquina de guerra", ao discorrerem sobre as ciências régia e nômade, Deleuze e Guattari (2007) nos ajudam nessa discussão quando fazem alusão à ideia de fenômenos fronteiriços. Ao partirem da concepção de que a ciência do Estado sempre busca impor sua forma de soberania às invenções da ciência nômade retendo dela aquilo de que pode apropriar-se, os autores (2007, p. 27) inferem: "O mais importante talvez sejam os fenômenos fronteiriços onde a ciência nômade exerce uma pressão sobre a ciência do Estado, e onde, inversamente, a ciência do Estado se apropria e transforma os dados da ciência nômade".

Assim, considerando as discussões-ações que temos realizado no campo do currículo entendemos que, mesmo sabendo da força impositiva nos cotidianos das escolas dos diferentes documentos oficiais prescritivos com suas ciências régias, textos esses que buscam fechar os sentidos do que pensamos ser currículo contribuindo, desse modo, para o surgimento de clichês, interessa-nos cartografar-problematizar os fenômenos fronteiriços.

Fenômenos que instituem-se em meio às situações em que os currículos tecidos em redes nos cotidianos exercem pressão sobre as ações do Estado e, inversamente, as ações do Estado, com suas prescrições, como a atual proposta de uma Base Nacional Comum Curricular (BNCC), buscam apropriar-se, desqualificar e, em alguns casos, 
invisibilizar esses currículos em redes assumidos por nós como criações cotidianas, como fluxos que não se deixam capturar, nem traduzir por completo porque são da ordem do devir. A esse respeito Deleuze e Parnet (2004, p. 12-13) afirmam que:

\begin{abstract}
Devir nunca é imitar, nem fazer como, nem se conformar a um modelo, seja de justiça ou de verdade. Não há um termo do qual se parta, nem um ao qual se chegue ou ao qual se deva chegar. Tampouco dois termos intermutáveis. A questão 'o que tu devéns?' é particularmente estúpida. Porque à medida que alguém devém, aquilo que devém muda tanto quanto ele próprio. Os devires não são fenômenos de imitação, nem de assimilação [...]. Uma conversa, poderia ser isso. Simplesmente o traçado de um devir [...]. Os devires são o que há de mais imperceptível. São atos que só podem estar contidos numa vida e expressos num estilo.
\end{abstract}

Propomos assim pensar currículo buscando romper com a possibilidade de sua representação fixa-definitiva em um sentido-clichê, indo ao encontro de sua condição de redes, de nomadismo, de composições e deslizamentos, de minoridade e de campos de disputas de sentidos, fazendo vazar toda e qualquer possibilidade de um significado único ou de determinismos conceituais, como o pretendido pelo texto da BNCC. Para tanto, temos usado expressões como currículo-nômade, currículo-menor, currículofluxo, currículo-em-redes, currículo-devir, currículo-acontecimento, currículo-fluido, entre outras, movidos pela ideia da impossibilidade de fechar um sentido para o que entendemos ser currículo e, ainda, pela pista dada por Deleuze e Guattari (2001, p. 20) quando disparam que "Conceitos são meteoritos, não mercadorias".

Pensamos em currículo então como movimento, como fluxo e não apenas como forma, ou produto que pode ser objetificado, medido e comercializado, como pretendem os defensores da BNCC. Apostamos na ideia de currículo como intensidades produzidas em meio às relações de poder que colocam-se nos planos lisos e estriados dos cotidianos das escolas.

\title{
Práticas-políticas curriculares cotidianas e resistência
}

Como já dito, a constituição do nosso campo problemático surgiu em meio aos fenômenos fronteiriços, isto é, nos intermezzos, nas fissuras, nas brechas e rizomas que insinuam-se nos cotidianos das escolas. Ao discutirem a potência do conceito de rizoma, Deleuze e Guattari (1996, p. 37) inferem que:

Um rizoma não começa nem conclui, ele se encontra sempre no meio, entre as coisas, inter-se, intermezzo. A árvore impõe o verbo 'ser', mas o rizoma tem como tecido a conjunção 'e... e... e.... Há nesta conjunção força suficiente para sacudir e desenraizar o verbo ser [...]. É que o meio não é uma média; ao contrário, é o lugar onde as coisas adquirem velocidade. 'Entre' as coisas não designa uma correlação localizável que vai 
de uma para outra e reciprocamente, mas uma direção perpendicular, um movimento transversal que as carrega uma 'e' outra, riacho sem início nem fim, que rói suas duas margens e adquire velocidade no meio.

Então, para nós, será com essa condição das situações fronteiriças que as políticas curriculares cotidianas acontecem. Sem idealizações, transcendências, generalizações ou determinismos, uma vez que são da ordem do acaso, dos acontecimentos e do caos. Para Deleuze \& Guattari (2007) não há sentido em perguntar-se sobre qual o sentido do acontecimento porque o acontecimento é o próprio sentido. Como os autores (2007, p. 177) nos ensinam:

Em todo acontecimento, há de fato o momento presente da efetuação, aquele em que o acontecimento se encarna em um estado de coisas, um indivíduo, uma pessoa, aquele que é designado quando se diz: pronto, chegou a hora; e o futuro e o passado do acontecimento só são julgados em função desse presente definitivo, do ponto de vista daquele que o encarna. Mas há, por outro lado, o futuro e o passado do acontecimento tomado em si mesmo, que esquiva todo presente porque está livre das limitações de um estado de coisas, sendo impessoal e pré-individual, neutro, nem geral nem particular, eventum tantum...; ou antes que não tem outro presente senão o do instante móvel que o representa, sempre desdobrado em passado-futuro, formando o que convém chamar de contra-efetuação.

A partir da realização de pesquisas com os cotidianos, temos nos interessado então em cartografar processos vividos nas escolas, sobretudo aqueles afetos às produções curriculares que resistem (Foucault in Revel, 2011) aos mecanismos de opressão e de tentativas de anulação das diferenças. Nessas pesquisas, buscamos nos situar à espreita dos acontecimentos, dos encontros, das conversas e das experiências, entre outros fluxos, movimentos, forças e intensidades que nos forçam a pensar os cotidianos das escolas como espaços-tempos de táticas-estratégias de resistências e permanentes aberturas ao devir. Como já dissemos, sem idealizações, transcendências ou generalizações, mas como produções de redes curriculares abertas ao involuntário da vida!

Ao problematizar a noção de resistência em Foucault, Revel (2011) observa que o referido termo é precedido na obra do autor por noções como transgressão e exterior. Em ambos os casos, tratava-se de descrever as maneiras como os indivíduos singulares conseguiam, de maneira voluntária ou fortuita, isto é, ao acaso, impediam o sucesso dos dispositivos de identificação, de classificação e de normatização do discurso. Ao desenvolver sua análise, a autora (2011, p. 127-128) infere que:

O termo resistência surge, então, a partir da década de 1970, com um sentido bastante diferente daquele que tinha a 'transgressão': a resistência se dá, necessariamente, onde há poder, porque ela é inseparável das relações de poder; acontece que ela estabelece as relações de poder exatamente quando ela é, por vezes, o seu resultado; na medida 
em que as relações de poder se encontram em toda parte, a resistência é a possibilidade de abrir espaços de lutas e de administrar possibilidades de transformação por toda parte. A análise dos laços entre as relações de poder e os focos de resistência é, assim, realizada por Foucault em termos de estratégias e de tática: cada movimento de um serve de ponto de apoio para uma contraofensiva do outro.

As discussões de Deleuze \& Guattari (2007) sobre os fenômenos fronteiriços e as ponderações, a partir de Foucault, de Revel (2011) sobre resistência, a nosso ver, nos forçam a pensar que as práticas cotidianas não podem ser reduzidas aos mecanismos de opressão nem de reprodução, mas pressupõem processos de produção de práticaspolíticas de currículo. Essa ideia nos tem estimulado a buscar uma noção de política mais complexa do que aquela defendida nos textos-discursos dos documentos governamentais. De fato, se é urgente perceber que as práticas são, também, teorias, igualmente é urgente perceber que elas são, sobretudo, políticas.

Entender as práticas-teorias curriculares cotidianas como políticas de currículo implica não só questionar algumas das dicotomias herdadas pela área da Educação do discurso hegemônico da ciência moderna, como cultura $x$ sociedade, teoria $x$ prática, sujeito $x$ objeto, entre outras, mas, sobretudo, implica colocar sob suspeita toda e qualquer proposta de fazer com que a prática torne-se política, isto é, implica ficarmos alerta para a ideia, tão presente nas escolas, de que é preciso conscientizar politicamente as pessoas, atitude que, a nosso ver, muitas vezes nega o fato de que, independentemente de suas condições, opções ou escolhas culturais, são sempre sujeitos políticos. Como defende Alves (2010, p. 49),

Para começar precisamos dizer que não existe, nas pesquisas com os cotidianos, entre
os inúmeros grupos que as desenvolvem, a compreensão de que existem 'práticas e
políticas [...] uma vez que entendemos que as políticas são práticas, ou seja, são ações de
determinados grupos políticos sobre determinadas questões com a finalidade explicitada
de mudar algo existente em um campo de expressão humana. Ou seja, vemos as políticas,
necessariamente, como práticas coletivas dentro de um campo qualquer no qual há,
sempre, lutas de posições diferentes e, mesmo, contrárias. Desta maneira, não vemos
como 'políticas' somente as ações que são mais visíveis. Os grupos não hegemônicos,
em suas ações, produzem políticas que, muitas vezes, não são visíveis aos que analisam
'as políticas' porque estes foram formados para enxergar, exclusivamente, o que é
hegemônico com o que aprenderam com o modo de pensar hegemônico.

Assim, ao entendermos que as práticas são também políticas de currículo, faz-se necessário favorecer tentativas de aproximação-mobilização das diferentes situações vividas nas escolas, assumindo a importância de pensar-se com os esses praticantes e não para ou sobre eles. Como temos defendido, essa atitude de pensar com o Outro nos tem levado à pista deixada por Certeau $(1994,1996)$ em termos de sua preocupação em estabelecer uma condição de empatia fora do comum com os envolvidos na produção dos dados. 
Ainda nessa direção é preciso dizer que a relação de proximidade com o Outro na pesquisa não resulta em uma abordagem pessoal, individualista, mas vai ao encontro do que se passa entre as pessoas, isto é, privilegia as relações que são estabelecidas com os encontros, as conversas, os acontecimentos, as experiências, entre tantas outras situações já acenadas por nós. Ou seja, interessam-nos, como já dito, os fenômenos fronteiriços, as situações involuntárias, os acasos, os intermezzos; e não as pessoas tomadas em suas identidades. Certeau (1994, p.37) corrobora com essa ideia ao considerar que:

O exame dessas práticas não implica um regresso aos indivíduos. O atomismo social que, durante três séculos, serviu de postulado histórico para uma análise da sociedade supõe uma unidade elementar, o indivíduo, a partir do qual seriam compostos os grupos e à qual sempre seria possível reduzi-los [...]. De um lado, a análise mostra antes que a relação (sempre social) determina seus termos, e não o inverso, e que cada individualidade é o lugar onde atua uma pluralidade incoerente (e muitas vezes contraditória) de suas determinações relacionais. De outro lado, e sobretudo, a questão tratada se refere a modos de operação ou esquemas de ação e não diretamente ao sujeito que é seu autor ou seu veículo.

Por fim, como já observado, entendemos que nossa aposta ético-estético-política nos currículos que resistem aos modos instituídos governamentais situa-se em um movimento micropolítico de resistência frente aos mecanismos de opressão e de controle do Estado, sobretudo nos dias atuais, com a imposição da referida Base Nacional Comum Curricular. Trata-se, em tese, de uma proposta de trabalho que busca dar visibilidade à dimensão teórico-epistemológica dos cotidianos das escolas e, ao mesmo tempo, potencializá-la.

Ou seja, sem desconsiderar a importância das discussões e análises que são realizadas no âmbito do próprio texto governamental, defendemos a necessidade de, com nossas pesquisas, fortalecer os movimentos de resistência e inventividade que acontecem na microfísica dos cotidianos escolares, nos diferentes espaços-tempos intersticiais das escolas, nas tensões que emergem com seus planos de imanência e nas multiplicidades daquilo que é vivido no dia a dia, por entender que é também nesses fenômenos fronteiriços (Deleuze, 2011) que a vida reinventa-se.

Ao discutir "Locais da cultura", Bhaha (1998, p. 20) nos ajuda nessa defesa quando entende que "É na emergência dos interstícios - a sobreposição e o deslocamento de domínio da diferença - que as experiências intersubjetivas e coletivas de nação [nationnes], o interesse e o valor cultural são negociados". Para ele (1998, p. 27), muito próximo do que pensa Deleuze, é exatamente nesses interstícios, nas fronteiras que as coisas começam a fazer-se presentes em um movimento ambivalente, uma vez que "O trabalho fronteiriço da cultura exige um encontro com 'o novo' que não seja patê do continuum do passado e presente. Ele cria uma ideia do novo como ato insurgente de tradução cultural". 
Insistimos, então, em uma atitude de pesquisa que possa compor com os cotidianos das escolas assumidos em sua dimensão estético-político-epistemológica. Daí nossa defesa da condição de autores de teorias-práticas curriculares para os praticantes dos currículos pois, como defende Bhabha (1998, p. 29), "É o espaço da intervenção que emerge nos interstícios culturais que introduz a invenção criativa dentro da existência".

Por isso insistimos em nossa proposta de pensar as práticas-políticas curriculares cotidianas como possibilidades de resistência aos clichês e à Base Nacional Comum Curricular, como sugere o título deste artigo.

\section{Referências}

ALVES, Nilda.(2008) Decifrando o pergaminho: o cotidiano das escolas nas lógicas das redes cotidianas. In: OLIVEIRA, Inês Barbosa de; ALVES, Nilda (Org.). Pesquisa nos/dos/com os cotidianos das escolas: sobre redes de saberes. Rio de Janeiro: DP\&A,p. 15-38.

. (2010). Redes educativas "dentrofora" das escolas exemplificadas pela

formação de professores. In: DALBEN, Ângela. et al. (Org.). Convergências e tensões no campo da formação e do trabalho docente. Belo Horizonte: Autêntica, p. 49-66.

BHABHA, Homi.(1998). O local da cultura. Belo Horizonte: UFMG, 1998.

CERTEAU, Michel de. A invenção do cotidiano: as artes de fazer. Petrópolis: Vozes, 1994.

DELEUZE, Gilles.(2012). Bergsonismo.(Ed.34). Rio de Janeiro.

. (2009). A imagem-movimento: Cinema I. Lisboa: Assírio \& Alvim.

. (2007a). Francis Bacon: Lógica da sensação. (2007ª). Rio de Janeiro: Zahar.

. (2007b).A imagem-tempo. Cinema II. São Paulo: Brasiliense.

. . (2007c) Lógica do sentido. São Paulo: Perspectiva.

(2006). Proust e os signos. Rio de Janeiro: Forense Universitária.

. (2000).Conversações. (Ed. 34). Rio de Janeiro.

DELEUZE, Gilles; GUATTARI, Félix.(2008ª) .Mil platôs: capitalismo e esquizofrenia. 
(Ed. 34). Rio de Janeiro.

. (2008b).Mil platôs: capitalismo e esquizofrenia. (Ed. 34). Rio de Janeiro.

. (2007). Mil platôs: capitalismo e esquizofrenia. Rio de Janeiro.

. (2001) O que é a filosofia? (Ed. 34). Rio de Janeiro.

. (1996) Mil platôs: capitalismo e esquizofrenia. (Ed. 34) Rio de Janeiro.

DELEUZE, Gilles; PARNET, Claire.(2004). Diálogos. Lisboa: Relógio d'Água.

FERRAÇO, Carlos Eduardo (Org.). (2016) ...Currículos em redes. Curitiba: Editora CRV.

. (2003). Eu, caçador de mim. In: GARCIA, Regina Leite (Org.). Método:

pesquisa com o cotidiano. Rio de Janeiro: DP\&A, p. 157-175.

FOUCAULT, Michel. (2015) Ditos e escritos: estratégia e poder. Rio de Janeiro:

Forense Universitária.

REVEL, Judith. (2011). Dicionário Foucault. Rio de Janeiro: Forense Universitária. 
Carlos Eduardo Ferraço Possui Licenciatura Plena em Física pela UFES (1981), Mestrado em Educação pela UFF (1989), Doutorado em Educação pela USP (2000) e Pós-Doutorado em Educação pela UERJ (2008, 2015). É professor associado IV da UFES, atuando nos Cursos de Mestrado e Doutorado em Educação na Linha de Pesquisa Docência, currículo e processos culturais. Desenvolve pesquisas na área de currículo desde 1999, com ênfase em currículo, cotidiano escolar, conhecimento em redes e filosofia da diferença. É bolsista de produtividade de pesquisa do CNPq, atuando como coordenador do GRPes Currículos, cotidianos, culturas e redes de conhecimentos (UFES-2007), vice coordenador do GRPes Currículos, narrativas audiovisuais e diferença (UERJ-2017) e coordenador do Núcleo de Pesquisa e Extensão em Currículos e Culturas (NUPEC) do Centro de Educação da UFES. É vice-presidente/ Região Sudeste da Associação Nacional de Pós-Graduação e Pesquisa em Educação/ ANPEd (2015-2017), membro da diretoria da Associação Brasileira de Currículo/ABdC (2015-2017), Coordenador da Comissão de Ética na Pesquisa em Educação da ANPEd (2017) e membro da Comissão de Ética do Fórum das Ciências Humanas, Sociais e Sociais Aplicadas (FCHSSA, 2017). Atuou como coordenador e vice-cordenador do PPGE/UFES e do GT 12 Currículo/ANPEd. Possui livros e capítulos de livros pelas editoras Palgrave Macmillan, De Facto, Cortez, DP et Alii, EDUFES e CRV, e artigos em periódicos especializados, dentre eles, Educação \& Realidade, Educação \& Sociedade, Ciência \& Educação, Currículos sem Fronteiras, Transnational Curriculum Inquiry e Revista e-Curriculum. No período de 2015 a 2017 ajudou a organizar três dossiês temáticos nos periódicos Revista Espaço do Currículo $(2015,2016)$ e Educação \& Realidade (2017), com previsão de organização de outros três dossiês nos periódicos Revista Quaestio (2017), Revista Teias (2017) e Revista Espaço do Currículo (2017). 